\title{
World at work: The electronics industry
}

\section{Koh, G Chan, E Yap}

\section{Spotlight on a diverse industry}

7 m he electronics industry employs millions of workers throughout the world and plays a significant role in the structure of the world's economy. Many multinational electronics industries retain their capital intensive operations in home countries, but locate their labour intensive operations in newly industrialising countries, because of the lower cost of labour and attractive financial and infrastructural incentives offered. In many developing and newly industrialising countries, the industry is a major contributor to employment and national economic growth.

The electronics industry is diverse with a wide spectrum of processes. Its sectors include semiconductor wafer fabrication, manufacture of printed circuit boards, the assembly of semiconductor devices and printed circuit boards, and assembly of the final electronic products. There are also many supporting industries that produce materials and components necessary to make the final product. These include those which manufacture metal and plastic parts, electrical parts such as storage media for hard disks, precision motors to run drives, transformers, switches, liquid crystal displays, and other electronic components.

In general, the processes in the electronics industry can be viewed as a series of work leading to the final product (table 1):

- Semiconductor wafer fabricationmarks the beginning of every electronic product where circuits are etched onto wafers made of silicon.

- Integrated circuit assembly-the preparation and testing of the encapsulated integrated chip.

- Printed circuit board (PrCB) fabrication-the boards usually made of a plastic resin compound which is heated, mixed with a filler material, laminated with metal, cleaned and etched, and subsequently shaved and drilled.

- Printed circuit board (PrCB) assembly-integration of various electronic components on the PrCBs which involves "stuffing" of components into the boards, cleaning, fluxing, soldering, trimming, and testing.
- Final product assembly-the assembled PrCB is then incorporated with various other components to form the final electronic product.

Each process step uses a peculiar set of chemicals and machinery, and thus has specific occupational health and safety concerns.

The workforce in the electronics industry is unevenly distributed. There are by far, more workers in the assembly processes than in the fabrication processes. The gender distribution is also uneven. Generally, more males work in the fabrication works, maintenance related tasks and management, while females dominate the assembly line tasks (fig 1). Employees are often required to perform shiftwork.

Besides controversy and concern of suspected chemical toxicities at the electronics workplace causing cancer and adverse reproductive outcomes,

Table 1 Work processes in the electronics industry

Semiconductor wafer fabrication
Crystal purification and growth
Wafer preparation
Epitaxy and oxidation
Photolithography
Doping and type conversion
Metallisation, interconnections and
packaging
Semiconductor assembly
Die separation
Die attach bonding
Wire bonding
Encapsulation
Housing and marking
Testing
Printed circuit board (PrCB) fabrication
Resin bonding
Impregnation
Laminating
Photomasking and etching
Cutting and drilling
Marking and testing
Printed circuit board (PrCB) assembly
Parts preparation
PrCB "stuffing"
Soldering, touch-up
Marking and testing
Final product assembly
Parts preparation
Parts assembly
Testing
Housing assembly
Marking and packaging

there is also the general concern that the environment has been affected as well, for huge quantities of hazardous waste and wastewater from electronics work would require disposal and remedial treatment.

\section{HAZARDS IN ELECTRONICS WORK \\ Chemical hazards}

There are numerous chemical hazards in the semiconductor wafer fabrication industry. The chemicals may be explosive, toxic, or corrosive. Examples include gases such as arsine, phosphine, diborane, ammonia, chlorine; doping agents containing arsenic; strong acids such as hydrofluoric and hydrochloric acids; and numerous solvents. Fortunately most of the chemicals are used in enclosed systems. Exposures may however occur during maintenance or repair work, or in the event of accidental leaks or spills.

Chemicals used in the assembly of electronics equipment are generally less toxic, but day to day exposures may be higher, as these chemicals may be used in non-enclosed or non-automated situations. Common chemicals include solvents, cleaning agents (for example, acids, alkalis), resins (for example, epoxy resins), soldering material (lead and tin alloys), and soldering fluxes (which may contain colophony, or other chemicals such as amines).

Organic solvents constitute a significant proportion of the chemicals used in the electronics industry. Its multiple applications as degreasers, diluents, cleansers, and chemical reactants make it present in almost all processes in electronics. The types and amounts of solvents used in the industry tend to change with the rapidly evolving technology in the industry. Some of the solvents used include isopropanol, nbutyl acetate, Freons, xylene, acetone, methanol, methoxy ethanol, petroleum distillates, trichloroethane, methylene chloride, tetra-chloroethylene, ethylene glycol, and methyl ethyl ketone.

The wide spectrum of chemicals used is a concern, and the possible health effects wide ranging. They can affect the skin (irritant and allergic contact dermatitis), respiratory system (asthma, irritation), and central nervous system (neuropyschological impairment). There is also some controversy that semiconductor workers have a higher incidence of adverse reproductive outcomes. It is also believed that a number of chemicals used are also potentially carcinogenic, but because the industry is relatively new, any increased cancer incidence would only show up years later in exposed workers. A recent investigation conducted by the Health and Safety 


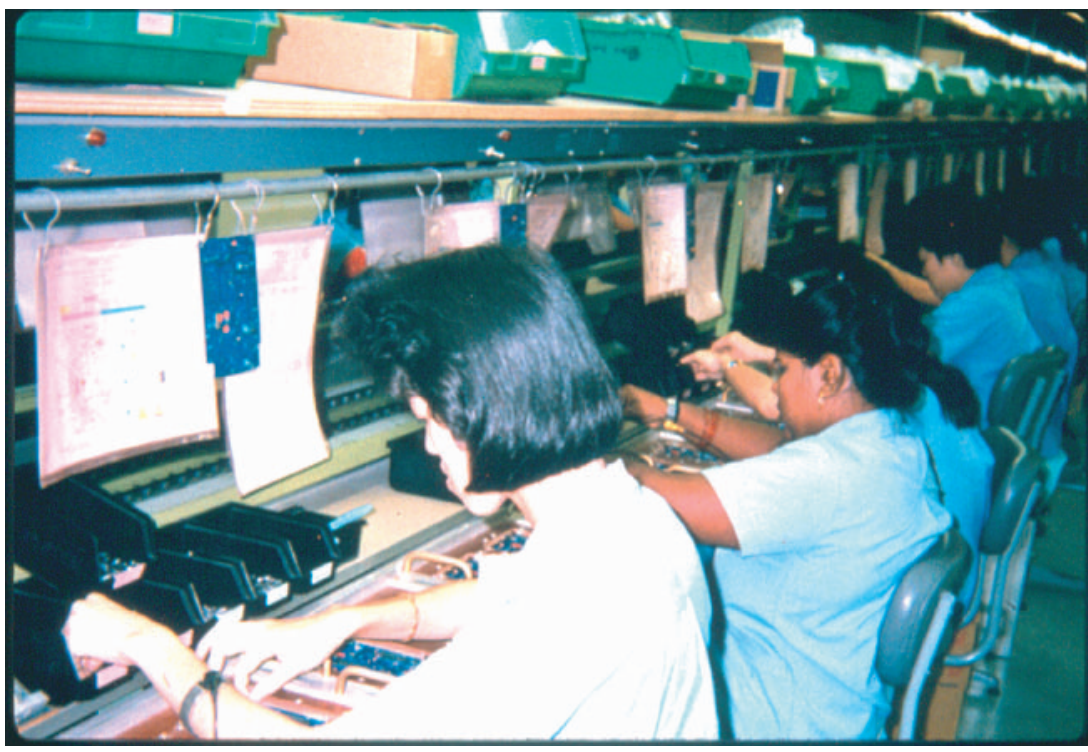

Figure 1 The majority of electronics assembly line workers are female.

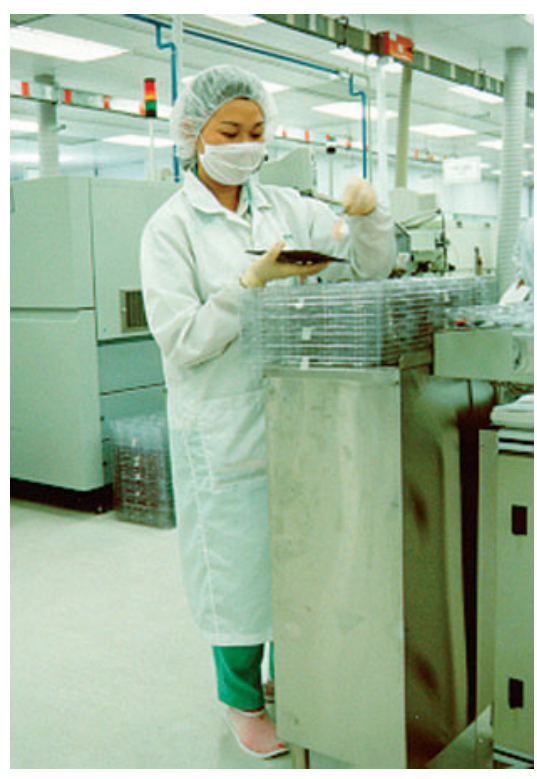

Figure 2 Typical attire of a clean room operator (the protective clothing is to protect the work materials and final product).

Executive in 1998 at a semiconductor plant in Scotland suggested that cancer incidence (especially lung cancer) of its workers was higher than that of the general population (McElvenny et al, 2001).

\section{Physical hazards}

Physical hazards may be present in electronics work. Among the hazards include noise and radiation. Ionising and non-ionising radiation are used for testing, quality control, and curing operations, but these are usually done as enclosed processes. Noise may be emitted by machinery such as motors, cutting equipment, and packaging machines. Low humidity has been described as a potential problem in clean room work, giving rise to dermatological symptoms.

Repetitive assembly line work or manual handling may lead to cumulative trauma disorders, backache, and strains of the musculoskeletal system. Prolonged visual inspection work, especially those that require a microscope, often results in eyestrain. Fortunately, such repetitive manual assembly line work and routine inspection tasks are increasingly being automated, and fewer workers will be exposed to such work in future. For the present, modifications to work tools and changes in work organisation, such as job rotation or implementation of appropriate workrest pauses, may help.

\section{Work in clean rooms}

Much of the production of semiconductors occurs in dust-free clean rooms. Clean rooms are also needed for other electronics work that requires dust free environments, for example, hard disk manufacture and storage media production. The rooms are required to be free of dust, and standards are applied according to the nature of end-products. High efficiency particulate absolute filtration units remove dust and air is recirculated to minimise further dust exposure. Workers also wear protective caps/hairnets, gowns, facemasks, and boots (fig 2) to prevent bodily dust from contaminating the work materials or products.

One health issue involves recirculated air. Workers are potentially exposed to recirculated solvents and other chemical fumes or vapours. The low humidity in clean room environments has been reported to cause itch and dermatitis.

\section{Other hazards}

Biological hazards are not routinely encountered in electronics work. However, communicable diseases may be easily spread to other workers. Contributory factors include the close proximity of workers in assembly lines, shared dining and hygiene facilities, crowded living conditions in factory dormitories, and possibly malnutrition. Such incidents largely occur in developing countries.

Adverse psychosocial factors in electronics work include the fast and unvarying pace of work in assembly lines, the monotonous nature of work, and rotating shifts.

Outbreaks of mass hysteria have been described among electronics workers in developing countries. The affected workers are usually young females with a low level of education, often coming from rural or village backgrounds. They have problems in adapting to the pace and nature of assembly line work. Such workers may also be found to be staying in dormitories, separated from their families, and this adds to the stress. In some countries, female electronics workers are also associated with risk behaviours such as amphetamine and alcohol use, as well as unprotected sex (Theobald, 2002)

\section{OCCUPATIONAL HEALTH AND SAFETY MANAGEMENT}

An effective occupational health and safety programme within the electronics workplace will involve the integration of specific programmes, for example, those targeting chemical safety and improved ergonomics, health surveillance, etc into a coherent and comprehensive health and safety management system. In addition, well informed workers and an effective surveillance system can prevent work related diseases and accidents.

In general, the programme will comprise the following framework:

- Identification of hazards.

- Implementation of control methods-the primary consideration being the complete removal or substitution with a less hazardous substance or process. If this is not feasible, an alternative approach would be to isolate the hazard using a combination of interventions, for example, enclosure, ventilation, and personal protection.

- Education of workers.

- Monitoring of environmental levels. 
- Monitoring of personal levels by exposure levels in biological samples or the surveillance of diseases and injuries.

\section{Chemical safety}

Toxic production chemicals should be replaced by non-toxic, or less toxic, alternatives, where possible. An actual example is the removal of glycol ethers from the workplace, following a study of increased miscarriage rate of women working in silicon wafer manufacturing rooms in the 1990s. In an industry where little is known about the long term health consequences of chemical exposure and its interaction, automation and enclosure of its work processes are important control measures to minimise exposure in general to chemical exposures.

\section{Engineering controls, education, and surveillance}

The measures to protect workers from the effects of harmful agents used are usually directed at maintaining exposure below a certain exposure limit that research and experience have shown to produce no adverse health effects. One of the more significant measures is the application of ventilation and enclosure systems, especially within the clean rooms where ineffective removal of chemicals and recycling of air could result in its stagnation and concentration. It is also important to regularly assess environmental levels of selected substances to ensure engineering controls are effective.

To prevent musculoskeletal and repetitive strain disorders, redesign of tools to transfer stress from smaller to larger joints, improving height relationships of different work surfaces, and orientation of work materials are just some of the ergonomic improvements that can be considered. Education on safe methods of manual handling is also important.

Other safety measures might include: (1) acid resistant and non-slip flooring; (2) exhaust ventilation in areas where toxic gases or fumes are given off; (3) protection of electrical equipment and material from wet or damp surroundings; (4) prohibition of eating, drinking, and smoking in work areas; (5) eyebath and first aid equipment; (6) protective clothing including gloves, rubber boots, eye protection, acid resistant garments made available and worn; and (7) standard procedures for manual handling, for example, handling of solid alkalis and dry acids with tongs or shovels.

Workers employed should be adequately trained for their duties and should undergo specific regular medical examinations to ensure that they are both fit for the job and free from harm acquired from the job. At these visits, they should also be educated about potential health hazards, recognition of early health effects, and practice of safe working techniques.

\section{CONCLUSION}

The electronics industry has experienced enormous global growth over the last quarter of a century. Like any other industry, occupational health hazards are present in electronics work. As the electronics workforce increases, there is a need for occupational and environmental medicine practitioners to be aware of the work processes in this industry, to recognise possible hazards, and to implement appropriate control measures to protect the health of its employees.

\section{APPENDIX}

Please visit the OEM website (www. occenvmed.com/supplemental) to view the video clips.

\section{Video clip 1: Assembly line electronics work}

This is a non-clean room environment. All the workers are females, and the work involves repetitive movement.

In the first segment, the worker wears an "earthing" wrist strap to remove static electricity, so as not to damage the electronics components she is handling. Nickel is present in the wrist strap, and it can cause allergic contact dermatitis among sensitised workers. Nickel allergic contact dermatitis can be avoided by replacement of the wrist strap with a nickel free alternative shown in fig 3.

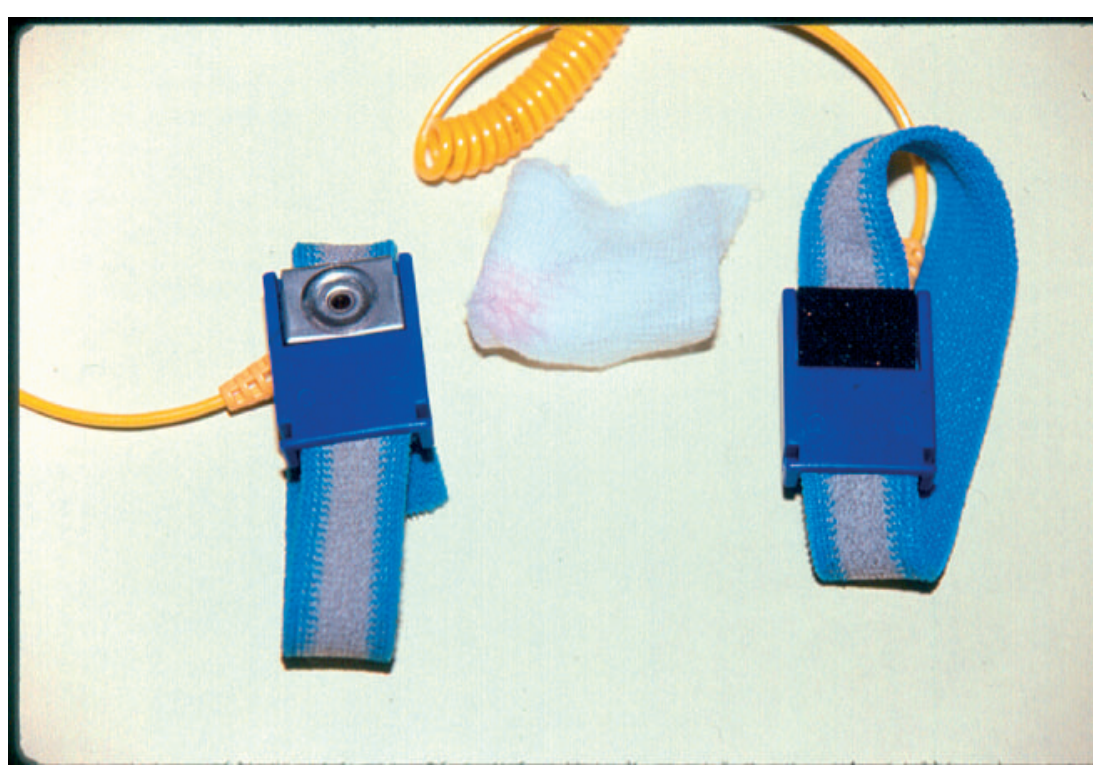

Figure 3 Earthing wrist straps - the strap on the left contains nickel (which may cause allergic dermatitis), while the one on the right does not.
In the second segment, the worker is cutting the protruding wires of the printed circuit board. She should be wearing appropriate eye protection, to avoid injury.

\section{Video clip 2: Clean room operations}

A clean room is required for any electronics work where dust particles may damage work materials or products. High efficiency particulate absolute filtration units remove dust, and air is recirculated to minimise further dust exposure. Workers also wear protective caps/hairnets, gowns, facemasks, and boots to prevent bodily dust from contaminating the work materials or products.

This clean room worker is involved in the fabrication of storage media for hard disk drives. The operator is involved in quality control work, which is repetitive in nature.

\section{Video clip 3: Control of workplace hazards}

This clean room worker is using a set of "tongs" for lifting cassettes. The inadequate design of the tongs places undue stress onto the wrist during prolonged work, and increases the risk of repetitive stress disorder. Adding a forearm support, as shown in fig 4 , would transfer the load from the wrist to the arm, which is stronger.

\section{ACKNOWLEDGEMENTS}

We wish to thank Mr Manuel Gamboa, Principal Media Producer from the Centre for Instructional Technology, National University of Singapore, for video clip 1 .

Occup Environ Med 2004;61:180-183 


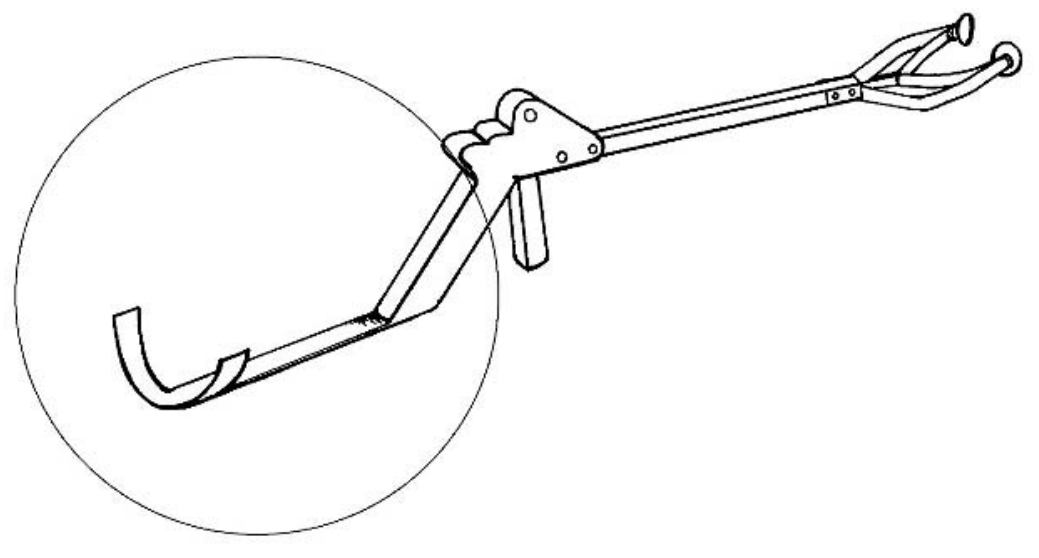

Figure 4 "Tongs" for lifting cassettes. Adding a forearm support, as shown in this illustration, would transfer the load from the wrist to the arm, which is stronger.

\section{Authors' affiliations}

D Koh, Professor and Head, Department of Community, Occupational and Family Medicine, National University of Singapore G Chan, Head of Preventive Medicine, Headquarters Medical Corps, Singapore Armed Forces

E Yap, Corporate Safety Program Manager, Seagate (RMO), Singapore

Correspondence to: Prof. D Koh, Department of Community, Occupational and Family Medicine, Faculty of Medicine, National University of Singapore; cofkohd@nus.edu.sg

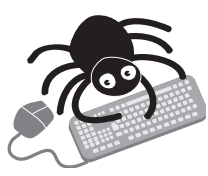

Video clips are available on the OEM website (www.occenvmed.com/supplemental)

\section{SELECTED REFERENCES}

Bowler RM, Mergler D, Huel G, et al. Neuropsychological impairment among former microelectronics workers. Neurotoxicology $1991 ; 12: 87-103$.

Burgess WA. Recognition of health hazards in industry, 2nd edn. New York: John Wiley and Sons, 1995.

Chen PC, Hsieh GY, Wang JD, et al. Prolonged time to pregnancy in female workers exposed to ethylene glycol ethers in semiconductor manufacturing. Epidemiology 2002; 13:191-6.
Chepesiouk R. Where the chips fall: environmental health in the semiconductor industry. Environ Health Perspect 1999:107:A452-7.

Correa A, Gray RH, Cohen R, et al. Ethylene glycol ethers and risks of spontaneous abortion and subfertility. Am J Epidemiol 1996;143:707-17.

de Peyster A, Silvers JA. Arsenic levels in hair of workers in a semiconductor fabrication facility. Am Ind Hyg Assoc J 1995;56(4):377-83.

Edelman P. Environmental and workplace contamination in the semiconductor industry: implications for future health of the workforce and community. Environ Health Perspect 1990;86:291-5.

Elliott RC, Jones JR, McElvenny DM, et al. Spontaneous abortion in the British semiconductor industry: an HSE investigation. Health and Safety Executive. Am J Ind Med 1999:36:557-72.

Elliott RC. Spontaneous abortion in the UK semiconductor industry: an HSE investigation-reply to "Open letter to the Greenock Telegraph". Int Occup Environ Health 1999:5:154-6.

Fowler BA, Yamauchi H, Conner EA, et al. Cancer risks for humans from exposure to the semiconductor metals. Scand J Work Environ Health 1993;19(suppl 1):101-3.

Fowler B, LaDou J, Osorio AM, et al. RE: Spontaneous abortion in the British semiconductor industry. Am J Ind Med 1999;36:584-5.

Gupta BN, Rastogi SK, Husain T, et al. A study of respiratory morbidity and pulmonary function among solderers in the electronics industry. Am Ind Hyg Assoc J 1991;52(2):45-51

McElvenny DM, Darntorn AJ, Hodgson JT, et al. Cancer among current and former workers at National Semiconductor (UK) Ltd, Greenock: results of an investigation by the Health and Safety Executive. Health and Safety Executive, 2001. Available on: http://www.hse.gov.uk/statistics/nsukrept.pdf.

Koh D, Lee HS, Chia HP, et al. Skin disorders among hand solderers in the electronics industry. Occup Med (Lond) 1994;44:24-8.
Koh D. Occupational dermatitis-What's new? Electronics industry. Clinics in Dermatology 1997; 15:579-86.

LaDou J, Rohm T. The international electronics industry. Int J Occup Environ Health 1998;4:1-18.

Lee HS, Koh D, Chia HP, et al. Symptoms, lung function, and diurnal variation in peak expiratory flow rate among female solderers in the electronics industry. Am J Ind Med 1994;26:613-19.

Luo JC, Hsu KH, Hsieh LL, et al. Lung function and general illness symptoms in a semiconductor manufacturing facility. J Occup Environ Med 1998:40:895-900.

Luo JC, Hsieh LL, Chang MJ, et al. Decreased white blood cell counts in semiconductor manufacturing workers in Taiwan. Occup Environ Med 2002:59:44-8.

Lipscomb JA, Fenster L, Wrensch $M$, et al. Pregnancy outcomes in women potentially exposed to occupational solvents and women working in the electronics industry. J Occup Med 1991 33:597-604.

McCurdy SA, Schenker MB, Samuels SJ. Reporting of occupational injury and illness in the semiconductor manufacturing industry. Am J Public Health 1991;81:85-9.

McCurdy SA, Pocekay C, Hammond SK, et al. A cross-sectional survey of respiratory and general health outcomes among semiconductor industry workers. Am J Ind Med 1995;28:847-60.

Pastides H, Calabrese EJ, Hosmer DW, et al. Spontaneous abortion and general illness symptoms among semiconductor manufacturers. J Occup Med 1988;30:543-51.

Sasaki T, Iwasaki K, Oka T, et al. Effect of working hours on cardiovascular-autonomic nervous functions in engineers in an electronics manufacturing company. Ind Health 1999;37:55-61.

Schenker MB, Gold EB, Beaumont JJ, et al. Association of spontaneous abortion and other reproductive effects with work in the semiconductor industry. Am J Ind Med 1995;28:639-59.

Schenker M, Beaumont J, Eskenazi B, et al. Final report to the Semiconductor Industry AssociationEpidemiologic study of reproductive and other health effects among workers employed in the manufacture of semiconductors. Davis, CA: University of California, 1992.

Sheehy JW, Jones JH. Assessment of arsenic exposures and controls in gallium arsenide production. Am Ind Hyg Assoc J 1993;54(2):61-9.

Theobald S. Gendered bodies: recruitment, management and occupational health in northern Thailand's electronics factories. Women Health 2002;35(4):7-26.

Upfal M. Liver enzymes among microelectronics equipment maintenance technicians. J Occup Med 1992;34:384-90.

Watson SI, Cain JR, Cowie H, et al. Development of a push-pull ventilation system to control solder fume. Ann Occup Hyg 2001;45:669-76.

Watterson A, Silberschmidt M, Pickvance S, et al. RE: Spontaneous abortion in the UK semiconductor industry. Am J Ind Med 1999:36:586.

Williams M. Microelectronics and semiconductors. Encyclopaedia of occupational health and safety, Vol. III, 4th edn. Geneva: ILO, 1998:83.1-83.33.

Woskie SR, Hammond SK, Hines CJ, et al. Personal fluoride and solvent exposures, and their determinants, in semiconductor manufacturing. Appl Occup Environ Hyg 2000;15:354-61. 